Portland State University

PDXScholar

4-1-1996

Postpollination mechanisms influencing mating

patterns and fecundity: an example from Eichhornia paniculata

Mitchell B. Cruzan

Portland State University

Follow this and additional works at: https://pdxscholar.library.pdx.edu/bio_fac

Part of the Plant Breeding and Genetics Commons

Let us know how access to this document benefits you.

Citation Details

Cruzan, M. B., and Barrett, S. H. (1996). Postpollination mechanisms influencing mating patterns. American Naturalist, 147(4), 576.

This Article is brought to you for free and open access. It has been accepted for inclusion in Biology Faculty Publications and Presentations by an authorized administrator of PDXScholar. Please contact us if we can make this document more accessible: pdxscholar@pdx.edu. 


\title{
POSTPOLLINATION MECHANISMS INFLUENCING MATING PATTERNS AND FECUNDITY: AN EXAMPLE FROM EICHHORNIA PANICULATA
}

\author{
Mitchell B. Cruzan* and Spencer C. H. Barrett \\ Department of Botany, University of Toronto, Toronto, Ontario M5S 3B2, Canada
}

Submitted December 1, 1994; Revised August 2, 1995; Accepted August 16, 1995

\begin{abstract}
Plant mating systems are influenced by the amount and genetic composition of pollen grains deposited on stigmas and by the ability of recipients to discriminate among pollen from different sources. We describe an experimental procedure that uses limiting and excess pollinations with mixtures of genetically marked pollen to partition the siring success of donors into three components: prefertilization gamete attrition (failure of male gametophytes before fertilization), pollen competitive ability (differences in pollen tube growth rate), and postfertilization gamete attrition (embryo abortion). Regression models for the relationships of pollen load size with each pollen's siring success and total recipient fecundity indicate that, for mixtures of self and outcross pollen, differences in gamete attrition, pollen competitive ability, and postfertilization success will have distinct and predictable effects on mating patterns and fecundity. Mating systems that rely on differences in pollen competitive ability result in outcrossing frequencies that increase with pollen load size, with seed production remaining high over a broad range of load sizes. In contrast, for mating systems governed by differences in gamete attrition, the frequency of outcrossed progeny will not vary greatly with pollen load size, but reduced fecundity will be expected over a wider range of pollen load sizes. These predictions were confirmed by analyzing the response of siring success and fecundity in response to pollen load size in the tristylous Eichhornia paniculata (Pontederiaceae). Experimental manipulations of the size and composition of pollen loads allow prediction of the frequency of outcrossed progeny produced under varying pollen environments.
\end{abstract}

The proportion of selfed and outcrossed progeny produced by hermaphroditic organisms has consequences for the partitioning of genetic variation within and among populations (Brown 1990; Hamrick and Godt 1990) and the level of genetic load maintained in populations (Lande and Schemske 1985; Jarne and Charlesworth 1993). Consequently, the mating system has a large influence on the evolutionary dynamics of hermaphroditic plant populations. The frequency of selfed and outcrossed seeds produced in plant populations can vary extensively among different species and within and among populations of a single species (reviewed in Schemske and Lande 1985; Barrett and Eckert 1990). Of particular interest are populations that produce mixtures of selfed and outcrossed offspring (mixed mating), not only because their existence is contrary to the predictions of most models of mating system evolution (Holsinger et al. 1984; Lande and Schem-

* Present address: Departments of Botany and of Ecology and Evolutionary Biology, University of Tennessee, Knoxville, Tennessee 37996-1100. 
ske 1985; Charlesworth et al. 1990) but also because they provide an opportunity to study the proximate ecological and physiological factors that contribute to mating system variation.

Mixed mating is strongly influenced by ecological factors including the activity and behavior of pollinators (Harding et al. 1974; Barrett et al. 1994; Cruzan et al. 1994) as well as postpollination physiological processes such as discrimination against particular pollen types (Jones 1928; Casper et al. 1988; Snow and Spira 1991; Cruzan and Barrett 1993) and postfertilization embryo abortion (Burbridge and James 1991; Montalvo 1992; Kärkkäinen and Savolainen 1993; Rigney et al. 1993). Although these ecological and physiological processes can have substantial influence on the frequency of outcrossed seed production in plant populations, there have been relatively few detailed studies examining these functional aspects of mating systems (Lloyd and Schoen 1992). The influence of floral biolog:y on mating system variation requires intrapopulation analysis of factors contributing to variation in outcrossing rates; however, most studies of mating system variation have made comparisons among populations (e.g., Harding et al. 1974; Barrett and Husband 1990). Research that has examined intrapopulation variation in outcrossing rates has concentrated on the ecological and demographic aspects of mating systems (e.g., Ritland and Ganders 1985; Schoen and Brown 1991; Motten and Antonovics 1992; Barrett et al. 1993; Cruzan et al. 1994), while the effects of postpollination processes have been all but ignored (Lloyd and Schoen 1992). A more complete understanding of the factors contributing to mating system variation will require an analysis of both the ecological and physiological factors that affect the siring success of pollen.

The complexity of mating in plants is reflected in the number of disparate approaches that have been employed for its study; population geneticist: use genetic markers to measure critical parameters such as the outcrossing rate (Clegg 1980; Ritland and Ganders 1985; Schemske and Lande 1985; Barrett and Eckert 1990; Brown 1990), physiologists and cell biologists investigate pollen-pistil interactions and the cellular aspects of pollen tube growth and fertilization (HeslopHarrison 1987; Dulberger 1992; Knox et al. 1992), while ecologists analyze: patterns of pollen dispersal and deposition (Galen and Stanton 1989; Harder and Thomson 1989; Thomson and Thomson 1989). Some effort has been made to examine the evolutionary consequences of patterns of self and outcross pollen deposition by Holsinger (1991), but postpollination processes were not considered in detail in his analysis. Although a knowledge of the intrinsic (physiological) and extrinsic (ecological) factors is necessary for understanding the maintenance and evolution of mixed mating systems, there has been little effort to establish functional relationships between the processes occurring at the physiological level and the patterns of mating that they produce.

Much of the work on the physiological control of plant mating has concentrated on self-incompatibility systems (Nettancourt 1977; Campbell and Lawrence 1981; Anderson et al. 1986). In the majority of cases self-incompatibility appears to be controlled by a single multiallelic locus, with the incompatibility response due to inhibition of pollen-carrying alleles that are identical to stylar alleles (Nettaniourt 1977). Theoretical treatments of the evolution of self-incompatibility systems 
have examined genetic factors that affect the ability of recipients to discriminate among self and outcross male gametes (Charlesworth and Charlesworth 1979; Uyenoyama 1988). An important parameter affecting the evolution of selfincompatibility is the frequency of selfing occurring at intermediate stages during the development of these systems (Uyenoyama 1988; Jarne and Charlesworth 1993). The examination of pollen-pistil interactions in mating systems that produce mixtures of selfed and outcrossed progeny may therefore provide insights into the evolution of self-incompatibility. However, there has been limited empirical work on incompatibility or other postpollination mechanisms affecting pollensiring ability in the context of mating system variation, so the impact of male gamete discrimination mechanisms on mating patterns is largely unknown.

Here we describe a procedure that approaches mating system variation from a functional perspective by characterizing patterns of pollen tube growth and ovule abortion. Our analysis identifies two distinct mechanisms of pollen discrimination with contrasting effects on mating and fecundity in response to variation in the pollen environment (i.e., the size and composition of pollen loads found under natural pollination conditions). We then use this approach to examine the mechanisms of pollen discrimination in the three style morphs of the tristylous Eichhornia paniculata (Spreng.) Solms-Laubach (Pontederiaceae). This analysis provides insights into the proximate factors affecting variation in outcrossing frequencies in natural populations as well as the evolution of heteromorphic incompatibility.

\section{DECOMPOSITION OF THE MATING SYSTEM}

The postpollination siring success of pollen may be affected by both pre- and postfertilization factors. Differences in the fertilization success of pollen can occur because of prefertilization failure of pollen tubes during growth in the pistil (i.e., pollen tube attrition; Cruzan 1989; Plitmann 1993) or because of differences among pollen types in their competitive ability (i.e., because of differences in the time required for germination or pollen tube growth rate; Jones 1928; Bateman 1956; Pfahler 1967; Ottaviano et al. 1988; Snow and Spira 1991). Incompatibility reactions contribute both to variation in levels of prefertilization attrition of pollen (self-incompatibility; Nettancourt 1977; Anderson et al. 1986; Heslop-Harrison 1987) and differences in growth rates of self and outcross pollen (cryptic selfincompatibility; Bateman 1956; Casper et al. 1988; Cruzan and Barrett 1993). Differences in the intrinsic growth ability of pollen affect both prefertilization pollen tube failure (Sayers and Murphy 1966; Cruzan 1989; Plitmann 1993) and pollen tube growth rate (Snow and Spira 1991; Mulcahy et al. 1992), but little is known about this phenomenon. After fertilization the siring success of pollen types may be further modified by differential abortion of embryos sired by different donors (Marshall and Folsom 1992; Montalvo 1992; Rigney et al. 1993). Each of these mechanisms may have different responses to changes in the pollen environment, and several may be functioning to influence the mating system.

\section{Patterns of Mating}

The response of the mating system to varying pollen environments will depend on the mechanisms controlling the siring success of pollen. Mechanisms that 
result in the failure of particular male gametes, either prezygotically (i.e., pollen tube attrition) or postzygotically (i.e., ovule abortion), may be influenced by stigma load compositions but not by stigma load size. This is because these gametes are effectively removed from the pool of pollen that may successfully sire seeds by processes that do not necessarily respond to the number of unfertilized ovules present. For this reason both pre- and postfertilization failure of male gametes are considered together here as one process (gamete attrition). Differential pollen tube growth rates, on the other hand, will affect the competitive ability of pollen. If the fertilization ability of pollen is based on growth rate, then relative success will depend on both the composition and size of the stigma load, with the relative success of the fastest-growing pollen types increasing with the total number of grains present. The relative contributions of male gamete attrition and differential growth rate to the discrimination process will determine the response of the mating system to varying pollen environments.

The degree to which the mating system is influenced by processes of gamete attrition or competitive interactions can be determined by examining the relative success of different pollen types under varying pollen load sizes. For each pollen type $i$ present on the stigma of a flower, the proportion of seeds sired $\left(F_{i}\right)$ will be affected by four factors: the proportion of pollen $i$ present on the stigma $\left(P_{i}\right)$, the ratio of the total number of grains present on the stigma to the number of ovules $(G / O)$, the level of differential gamete attrition $\left(\delta_{i}\right.$, the relative rate of failure of each pollen type $i$ or zygotes fertilized by each pollen type), and the competitive ability of pollen $i\left(\alpha_{i}\right.$, the relative growth rate of each pollen type $i$ ). When $G / O$ $<1$, the proportion of seeds sired depends only on a pollen type's frequency and its level of attrition; thus,

$$
F_{i}=P_{i}+\delta_{i}
$$

Values of $\delta_{i}$ can be either positive or negative and sum to zero for all pollen types present. Once the number of grains on the stigma exceeds the number of ovules $(G / O>1)$, there is potential for competition among pollen types. Under these conditions, the number of seeds sired by a pollen type is given by the regression

$$
F_{i}=\left(P_{i}+\delta_{i}\right)+\alpha_{i} P_{i}[(G / O)-1],
$$

where $\alpha_{i}$ is the slope of the relationship. Values of $\alpha_{i}$ lie between 1.0 and -1.0 , with a positive value indicating an increase in the proportion of ovules fertilized as $G / O$ increases (fig. $1 A$ ). Since values of $\alpha$ are deviations from the mean of the pollen tube growth rates for all pollen types present in the pollen load, their sum will be zero. When differences in pollen competitive ability exist, the proportion of seeds sired by different pollen types will depend on the number of pollen grains present. Even when $\delta_{i}$ is near zero, very large pollen loads can lead to the complete exclusion of all but one pollen type (fig. $1 A$ ).

\section{Patterns of Fecundity}

The mechanism of discrimination among pollen types will also have consequences for the fecundity of plants (fig. $1 B$ ). With no gamete attrition, seed production will be directly proportional to the pollen load size up to the point at 

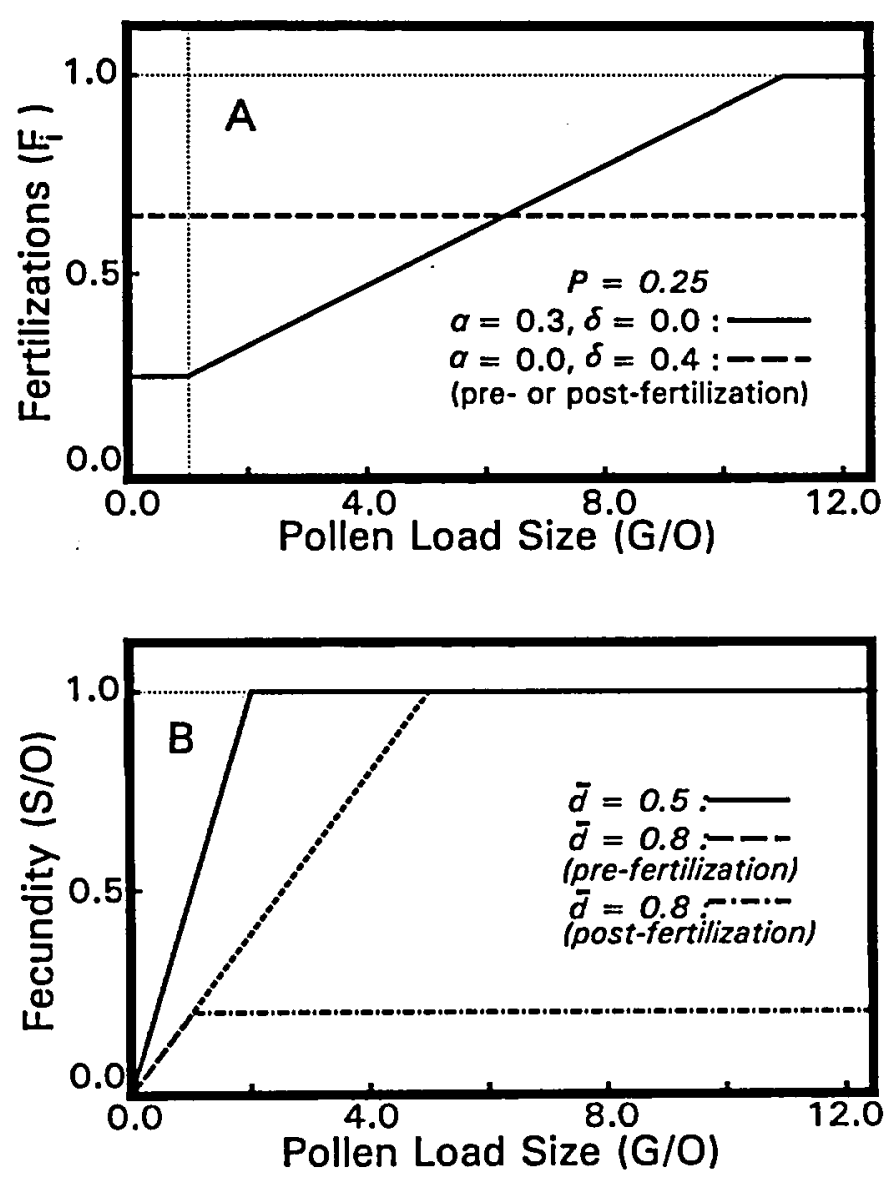

Fig. 1.-The fertilization success of pollen $(A)$ and the seed production by flowers $(B)$ in response to the size of the pollen load. For both relationships the proportion of outcross pollen is $25 \%$ of the pollen mixture applied to the stigma $\left(P_{i}=0.25\right)$. The fertilization success of outcross pollen $(A)$ is controlled by either its competitive ability (solid line) or its differential attrition (dashed line). The expected fecundity $(B)$ depends on the average attrition of the pollen mixture, and the maximum fecundity depends on whether attrition is pre(solid and dashed lines) or postfertilization (dot-dash line).

which the number of grains on the stigma exceeds the number of ovules. For the few species that have been examined, however, a direct correspondence between the number of pollen grains present on the stigma and the number of seeds set has not been found (see, e.g., Shore and Barrett 1984; Snow 1986; Cruzan 1989), which indicates that not all pollen grains are effective at producing seed. The seed set expected for a pollen load can be predicted from the weighted average of attrition values for all pollen types present $\left(\bar{d}=\Sigma P_{i} d_{i} / n\right)$, where $\bar{d}$ is the average attrition of the pollen mixture, $d_{i}$ is the level of attrition for the pollen type $i$, and $n$ is the number of pollen types present. Values of $d_{t}$ are not equivalent to differential gamete attrition, which represents a deviation from the mean attri- 
tion level for the pollen load $\left(\delta_{i}=d_{i}-\bar{d}\right)$. The number of ovules maturing, into seeds $(S)$ will be equal to the number of grains present on the stigma that are not subject to attrition,

$$
S=G(1-\bar{d}),
$$

up to the point at which all ovules have been fertilized $(S / O=1$; fig. $1 B)$. The maximum fecundity that can occur depends on whether attrition occurs pre- or postzygotically. When one or more of the pollen types suffer attrition during pollen tube growth, the rate at which seed set increases with pollen load size will be reduced, but the maximum seed set will not be affected (fig. $1 B$ ). Since fertilization of an ovule by a gamete destined to fail effectively destroys it, postzygotic attrition reduces both the rate at which seed set increases and the maximum seed production that can be attained (fig. $1 B$ ).

The above analyses indicate that both pre- and postfertilization processes will alter the siring success of different pollen types from the frequency of pollen types present on the stigma. By examining the response of total seed production and the frequency of fertilization by different pollen types under varying pollen loads, the contribution of differential pollen tube growth and gamete attrition to the mating system can be determined. Here we use controlled pollinations with mixtures of genetically marked pollen to estimate the levels of gamete attrition and competitive ability for different pollen types in the three style morphs of tristylous Eichhornia paniculata. We chose this species to assess the power of our procedure to distinguish among postpollination mechanisms influencing mating system variation because considerable information was already available on both outcrossing rate variation (Glover and Barrett 1986; Barrett and Husband 1990; Barrett et al. 1993) and postpollination reproductive processes (Morgan and Barrett 1989; Cruzan and Barrett 1993). Preliminary studies suggested that different mechanisms of pollen discrimination were present in the floral morphs of this species, which enabled us to assess the utility of our procedure at the intraspecific level. Such an approach avoids the likely confounding effects of phylogenetic history on comparative studies of postpollination mechanisms at the species level.

\section{METHODS}

Eichhornia paniculata is an annual emergent aquatic native to northeastern Brazil and the Caribbean Islands of Cuba and Jamaica (Barrett 1985). Plants bear reproductive organs at three different levels in flowers, with the stigma occupying one level (L, M, or S morphs for long-, mid-, and short-styled plants), and two sets of anthers occupying the other two levels $(1, \mathrm{~m}$, and $\mathrm{s}$ for long-, mid-, and short-level anthers). Following Darwin (1877), pollen transfer between anthers and stigmas of the same level is termed legitimate, whereas illegitimate pollination occurs when pollen transfer is between anthers and stigmas that are not of equivalent height. Legitimate pollinations can only occur between morphs and are, therefore, always outcross matings. Illegitimate pollinations can be self-matings when pollen transfer is in the same plant, or they can be outcross matings as either intra- or intermorph pollinations. 
Plants used in this study were derived from a single trimorphic population (B46) in Brazil (Barrett and Husband 1990). Field-collected seed from open-pollinated flowers (a total of approximately 50 families) were grown, and the resulting plants were crossed to produce a second generation. Plants homozygous for one of three $A A T-3$ alleles were selected from this base population. The use of more than one individual from the same seed family was avoided to ensure that plants used were an unbiased sample of the population.

Crosses were made by collecting pollen of the same anther level from individuals homozygous for the same allele. An effort was made to reduce the effects of individual variation among donors by combining pollen from several donors of each pollen type. Pollinations were made by placing pollen from the three anther levels in glass vials and using a piece of thick nylon fishing line to mix pollen and apply it to stigmas. Initial tests with I and s pollen, which can be distinguished on the basis of size under the microscope, indicated that this method produced nearly equal and homogeneous mixtures of pollen. Stigmas were collected $6 \mathrm{~h}$ after pollination and fixed in $70 \%$ ethanol. Stigma removal after $6 \mathrm{~h}$ has no apparent affect on fruit and seed set (M. B. Cruzan, unpublished data). Fruits were collected when mature, $10 \mathrm{~d}$ after pollination. The number of germinated pollen grains on stigmas was counted after staining with $0.1 \%$ basic fuchsin (Cruzan and Barrett 1993). Seeds from each fruit were counted, and 20 seeds for each cross were assayed for their AAT-3 genotype with previously described methods (Cruzan and Barrett 1993).

Pollinations with mixtures of pollen were used to examine the effect of the number of grains of each pollen type on their fertilization success in each of the three style morphs. Each pollen type is capable of producing full seed set in the three floral morphs following single-donor crosses (Barrett 1985; Kohn and Barrett 1992). The number of pollen grains of each type was manipulated in two contrasting ways: the composition of the stigma load was altered while holding the total number of grains applied constant, and the total number of grains present on the stigma was changed while holding the composition of the stigma load constant.

\section{Stigma Load Composition}

Flowers of the $\mathrm{L}, \mathrm{M}$, and $\mathrm{S}$ morphs were pollinated with either an equal mixture of the three pollen types or a mixture that consisted of $50 \%$ legitimate pollen. Equal pollen mixtures ( $33 \%$ of each pollen type) were made by collecting anthers from three flowers from each of three donors for each level. Legitimate-biased pollen mixtures (50\% legitimate and $25 \%$ of each illegitimate pollen type) were made by collecting pollen from four flowers from each of three donors for the legitimate anther level and two flowers from each of three donors for the two illegitimate anther levels. Pollen production by the three anther levels in E. paniculata shows no consistent pattern across the populations examined (Barrett 1985) and, compared with heterostylous species with strong self-incompatibility systems, is nearly equal (see Ganders 1979). The same donors were used for both the equal and biased pollen mixtures, and a different set of donors was used each day. Donor morph and $A A T-3$ genotype were rotated among anther levels each 
day so that all possible morph and genotype combinations were used with each anther level over a 6-d period. A total of nine homozygous recipients per morph, three of each $A A T-3$ genotype, were pollinated. A group of four or five recipients were used each day that included one or two plants of each morph. Eight flowers on each recipient were pollinated, with four flowers receiving pollen from the equal mixture and four receiving pollen from the biased mixture. Germinated pollen grains were counted for each pollination, and seeds were counted and assayed as previously described (Cruzan and Barrett 1993).

\section{Pollen Dosage}

Different amounts of pollen from an equal mixture of the three pollen types were applied to stigmas to examine the effect of total pollen number on the fertilization success of each pollen type. All three anthers from a level were collected from three flowers of three individuals of the same morph and $A A T-3$ genotype. Donor morph and $A A T-3$ genotype were rotated among anther levels each day as described above. A total of nine recipients of each morph, three of each genotype, were pollinated over a 6-d period (as above). To obtain an even distribution of values across the range of pollen load sizes, pollen was placed on either one of the three stigma lobes, two lobes, or all three lobes. A total of six flowers on each recipient were pollinated, with two flowers receiving each pollen load size. The number of germinated pollen grains present on stigmas and seeds produced was counted as previously described (Cruzan and Barrett 1993).

\section{Data Analysis}

Data from the pollen load composition and dosage experiments were analyzed as the proportion of seeds fertilized by each pollen type for each pollination. The differences between the even and biased treatments for their stigma load sizes, number of seeds set, and the frequency of legitimate fertilizations were tested with $t$-tests. The deviation of each pollen type's siring success from a random expectation was tested with $t$-tests for each mean's difference from a value of zero. Means for stigma load size, number of seeds set, and siring success were compared in the pollen dosage experiment in one-way ANOVAs with the general linear models (GLM) procedure of SAS (SAS Institute 1985). All data were appropriately transformed to meet normality assumptions.

Ovule number $(O)$ was estimated for flowers with the maximum seed set obtained on each plant and the predicted relationship between flower position and seed number per flower. Seed set on inflorescences decreases for flowers on lateral branches that are more distal to the apex of the inflorescence $\left(R^{2}=0.81\right.$, $P<.05 ;$ M. B. Cruzan, unpublished data), which suggests that they produce fewer ovules. We used this relationship and the maximum number of seeds produced by a flower on the same inflorescence to estimate ovule number for each flower.

\section{Patterns of Mating}

The equal-mixture treatment of the stigma load composition experiment was pooled with the pollen dosage experiment after using ANCOVA to determine 
that the data were homogeneous (ANCOVA, $P>.1$ for comparisons of slopes of $G$ on $F_{i}$ ). This combined data set was then used to estimate the attrition and competitive ability of each pollen type in each morph. The siring success of each pollen type was calculated as the proportion of assayed seeds fertilized by pollen type $i$. Values of siring success of each pollen type were subtracted from $F_{i}^{\prime}$, the expected level for each pollination $\left(F_{i}^{\prime}=F_{i}-P_{i}\right.$; where $P_{i}$ is 0.33$)$, to give the deviation from random fertilization. This transformation then allowed the direct estimation of the level of gamete attrition as the deviation from a zero intercept and pollen competitive ability as the slope by means of a modification of equation (2) $\left(F_{i}^{\prime}=\delta_{i}+\alpha_{i} G\right)$, for each pollen type in each morph. The deviations from random fertilization were used as the dependent variables in regression models with the total number of grains as the independent variable in calculations using the regression (REG) procedure of SAS (SAS Institute 1985).

\section{Patterns of Fecundity}

The combined data set of the equal mixture treatment from both experiments was examined to assess changes in fecundity after pollination with different numbers of pollen grains. The relationship between the relative fecundity of flowers and the number of pollen grains per ovule was examined for each morph by means of nonlinear regression analysis (NLIN procedure; SAS Institute 1985). Since the dispersion of the data made it impossible to fit a segmented linear model, an exponential regression model was used; it gave

$$
S / O=1-\left(\frac{G / O_{\max }-G / O}{G / O_{\max }}\right)^{k},
$$

where $G / O_{\max }$ is the maximum pollen load size observed (for these data $G / O_{\max }$ $=8.11)$ and $k$ is an exponent describing the shape of the relationship. For values of $k$ greater than one, the defined relationship is initially steep and decelerates as $S / O$ approaches full fertilization $(S / O=1.0)$. Larger values of $k$ produce steeper initial curves and are indicative of a lower value for $\bar{d}$.

\section{RESULTS}

\section{Stigma Load Composition}

The mean numbers of pollen grains present on stigmas of the three floral morphs of Eichhornia paniculata and the mean numbers of seeds set did not differ between the equal and biased pollination treatments (table 1). In each morph, legitimate pollen had a higher siring success than either of the two illegitimate pollen types after pollination with equal pollen mixtures. The fraction of seeds sired by legitimate pollen increased for the biased treatment as expected, and this increase was directly proportional to its frequency in stigma loads in all three morphs (table 1). This is apparent from the observation of the same pattern of deviations from expected fertilization in the equal and biased treatments (fig. 2). 
TABLE :

Mean Pollen load Sizes, Seed Production, and the Proportion of Legitimate Fertilizations after Equal and Biased Pollinations in EjchHornia paniculata

\begin{tabular}{|c|c|c|c|c|}
\hline Variable & $\begin{array}{c}\text { Equal } \\
(N=31)\end{array}$ & $\begin{array}{c}\text { Biased } \\
(N=33)\end{array}$ & $t$ & Probability \\
\hline \multirow[t]{2}{*}{$\begin{array}{l}\text { Morph L: } \\
\text { Pollen grains } \\
\text { Seed number } \\
\text { Legitimate fertilizations }\end{array}$} & $\begin{array}{c}370.5(14.0) \\
109.6(1.6) \\
.60(.03)\end{array}$ & $\begin{aligned} & 375.6(12.5) \\
& 110.9(1.7) \\
& .80(.02)\end{aligned}$ & $\begin{array}{r}.27 \\
.57 \\
37.03\end{array}$ & $\begin{array}{r}.784 \\
.573 \\
<.001\end{array}$ \\
\hline & $\begin{array}{c}\text { Equal } \\
(N=32)\end{array}$ & $\begin{array}{l}\text { Biased } \\
(N=33)\end{array}$ & $t$ & Proba'bility \\
\hline \multirow[t]{2}{*}{$\begin{array}{l}\text { Morph M: } \\
\text { Pollen grains } \\
\text { Seed number } \\
\text { Legitimate fertilizations }\end{array}$} & $\begin{array}{c}244.7(15.1) \\
92.0(4.5) \\
.49(.03)\end{array}$ & $\begin{aligned} & 267.8(13.3) \\
& 97.5(4.2) \\
& .66(.03)\end{aligned}$ & $\begin{array}{r}1.15 \\
.67 \\
22.97\end{array}$ & $\begin{array}{r}.253 \\
.502 \\
<.001\end{array}$ \\
\hline & $\begin{array}{c}\text { Equal } \\
(N=27)\end{array}$ & $\begin{array}{c}\text { Biased } \\
(N=25)\end{array}$ & $t$ & Probajility \\
\hline $\begin{array}{l}\text { Morph S: } \\
\text { Pollen grains } \\
\text { Seed number } \\
\text { Legitimate fertilizations }\end{array}$ & $\begin{array}{c}254.8(11.5) \\
92.6(5.9) \\
.60(.04)\end{array}$ & $\begin{array}{cl}285.8 & (20.7) \\
92.2 & (6.2) \\
.69 & (.04)\end{array}$ & $\begin{array}{r}1.33 \\
.05 \\
8.11\end{array}$ & $\begin{array}{r}.196 \\
.963 \\
<.001\end{array}$ \\
\hline
\end{tabular}

Note. - Standard errors are given in parentheses. For each variable in each morph, the equal (33\% legitimate) and biased (50\% legitimate) pollination treatments are compared with i-tests.

\section{Patterns of Mating}

The response of the seed-siring success of legitimate pollen to pollen load size differed among the three floral morphs, which indicates different contributions of gamete attrition and pollen competitive ability. The fraction of seeds sired in the $\mathrm{L}$ and $\mathrm{M}$ morphs tended to increase for legitimate pollen and to decrease or remain constant for illegitimate pollen types as the number of grains on the stigma increased (table 2; fig. 3). Nonzero slopes indicate that pollen's competitive ability is largely responsible for determining the siring success of different pollen types in these morphs. In the $\mathbf{S}$ morph, however, there was no change in the fraction of seeds sired by the different pollen types over the range of different stigmal load sizes (table 2). Fertilization success in this morph was mostly determined by the level of gamete attrition, as indicated by nonzero intercepts for $I$ and $s$ pollen (table 2; fig. 3). Evidence for the role of differential gamete attrition in the $S$ morph is also provided by differences in the seed-siring success of different pollen types in small pollen loads. If only those pollinations in the S morph that were pollen limited are examined (i.e., pollen loads that set $<20 \%$ fewer seeds than other fruits on the same plant), then legitimate pollen maintains a strong siring advantage $\left(F_{i}^{\prime}=-0.20,0.05\right.$, and 0.16 for $1, \mathrm{~m}$, and s pollen, respectively; $N=$ 19). There were also high levels of pollen attrition for s pollen in both the $J$, and $M$ morphs, which resulted in the positive intercepts for $m$ pollen in the $L$ morph and I pollen in the M morph (table 2). 


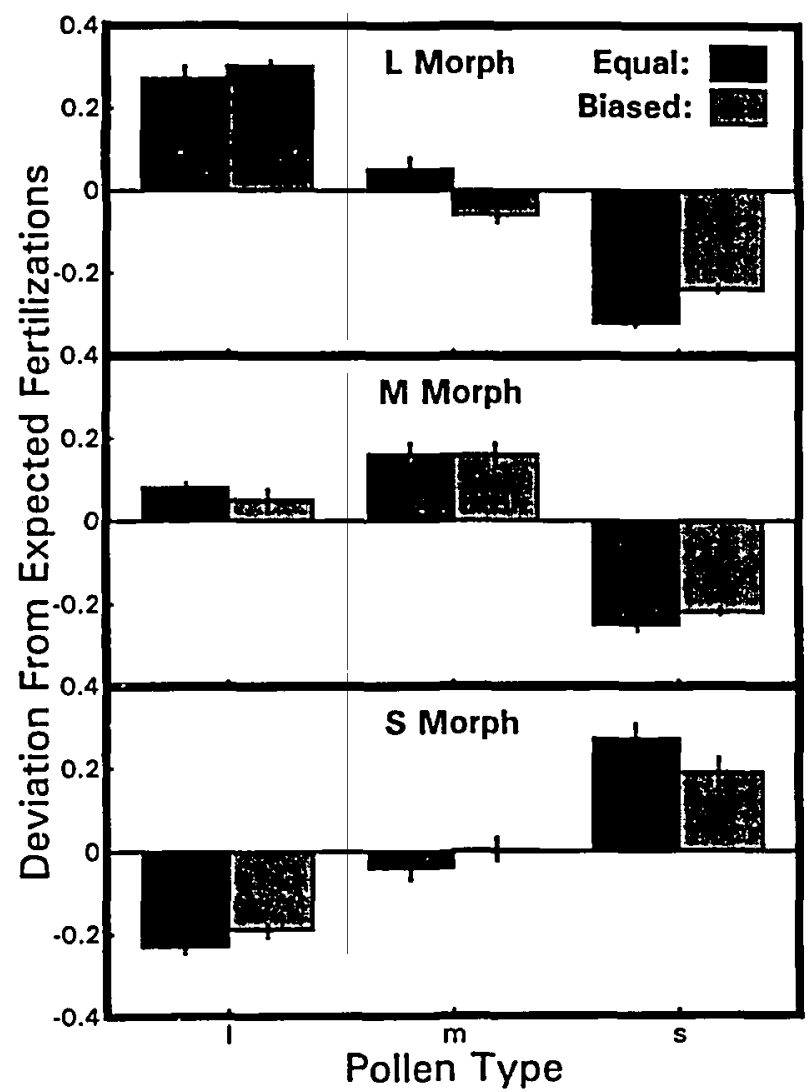

Fig. 2.-Fertilization success of the three pollen types in the three style morphs of Eichhornia paniculata after pollination with equal pollen mixtures $\left(P_{i}=0.33\right)$ and biased pollen mixtures $\left(P_{i}=0.5\right.$ for legitimate and 0.25 for both illegitimate pollen types). Data are presented as deviations from the expected level of fertilization.

\section{Patterns of Fecundity}

In the pooled data set, pollen load size tended to be greatest in the $\mathrm{L}$ morph, intermediate in the $\mathrm{M}$ morph, and least in the S morph (table 3), which probably reflects morph-specific differences in stigma area. Seed number increased with pollen load sizes in all three morphs (L morph, $r=0.57, P<.01 ; M$ morph, $r$ $=0.52, P<.01 ; \mathrm{S}$ morph, $r=0.75, P<.01 ;$ fig. 4$)$. The increase in seed number with pollen load size was asymptotic in the $\mathrm{L}$ and $\mathrm{M}$ morphs, as indicated by a significant negative quadratic term in polynomial regressions $(P<.05$ for both morphs), but linear in the $S$ morph $(P>.6$ for the quadratic term). The linear components of these relationships indicate that the increase in seed set with pollen load size occurred at a greater rate in the $\mathrm{L}$ and $\mathrm{M}$ morphs (slope $=0.37$ and 0.47 for $\mathrm{L}$ and $\mathrm{M}$ morphs, respectively, $P<.001$ for both) than in the $\mathrm{S}$ morph (slope $=0.22, P<.001$; for test of heterogeneity of slopes among morphs, $F=7.24, P<.001)$. 
TABLE 2

Regression analyses of Pollen load Size on Fertilization

Success of Each Pollen Type in EichHornia paniculata

\begin{tabular}{lrrrr}
\hline \hline Pollen & Intercept & Probability & \multicolumn{1}{c}{ Slope } & Probability \\
\hline Morph L: & & & & \\
I & .07 & .14 & .0016 & $<.01$ \\
m & .12 & $<.01$ & -.0005 & .22 \\
s & -.19 & $<.01$ & -.0011 & $<.01$ \\
Morph M: & & & & \\
I & .10 & $<.02$ & .0001 & .92 \\
m & -.04 & .31 & .0021 & $<.01$ \\
s & -.05 & .07 & -.0022 & $<.01$ \\
Morph S: & -.24 & $<.01$ & .0003 & .57 \\
I & .04 & .46 & -.0006 & .40 \\
m & .21 & $<.01$ & .0003 & .73 \\
s & .21 &
\end{tabular}

Note.-Probabilities are from t-tests for the difference from a zero intercept or the difference from a zero slope.

By transforming seed production into relative fecundity and using equation (4), we can examine the fit of the data to model predictions and determine whether levels of pre- and postfertilization gamete attrition differ among the floral morphs. As predicted, relative fecundity increased rapidly when pollen grain numbers were small and remained fairly constant over a range of larger pollen loads (fig. 4). Values of exponents for these relationships were similar for the $L$ and $M$ morphs ( $k=6.94$ and 6.98 for $\mathrm{L}$ and $\mathrm{M}$ morphs, respectively), but $k$ was signifcantly smaller in the $S$ morph $(k=5.47$; fig. 4$)$, as indicated by $95 \%$ confidence intervals that did not overlap the values obtained for the $\mathrm{L}$ and $\mathrm{M}$ morphs (lower $=5.67$ and 5.81 for the $L$ and $M$ morphs, respectively, and upper $=6.56$ for the $\mathrm{S}$ morph). Comparisons indicate that the exponential model explains a significantly larger portion of the variation than a linear model with a zero intercept in all three morphs $(P<.001$ for the increase in model sums of squares tested over the error mean square for the linear model for all floral morphs). Examining the initial slope $(b)$ of the exponential relationships gives an estimate of the value of $\bar{d}$ for each morph $(d \approx 1-b)$. For values of $G / O$ less than one, the slope of the line was greater in the $\mathrm{L}$ and $\mathrm{M}$ morphs $(b=0.60$ and $\bar{d}=0.40$ for both morphs) than in the $S$ morph $(b=0.51$ and $\bar{d}=0.49 ;$ fig. 4$)$, which indicates that average male gamete attrition levels were higher in the $S$ morph. Since the maximum levels of fecundity were similar in the three morphs (fig. 4), the higher levels of gamete attrition in the $\mathrm{S}$ morph probably occurred prior to fertilization.

\section{DISCUSSION}

By decomposing mating into its component processes, we have identified two proximate mechanisms responsible for producing differences in the siring success of different pollen types. The two mechanisms, gamete attrition and pollen competitive ability, display distinct responses to varying pollen loads and result in 


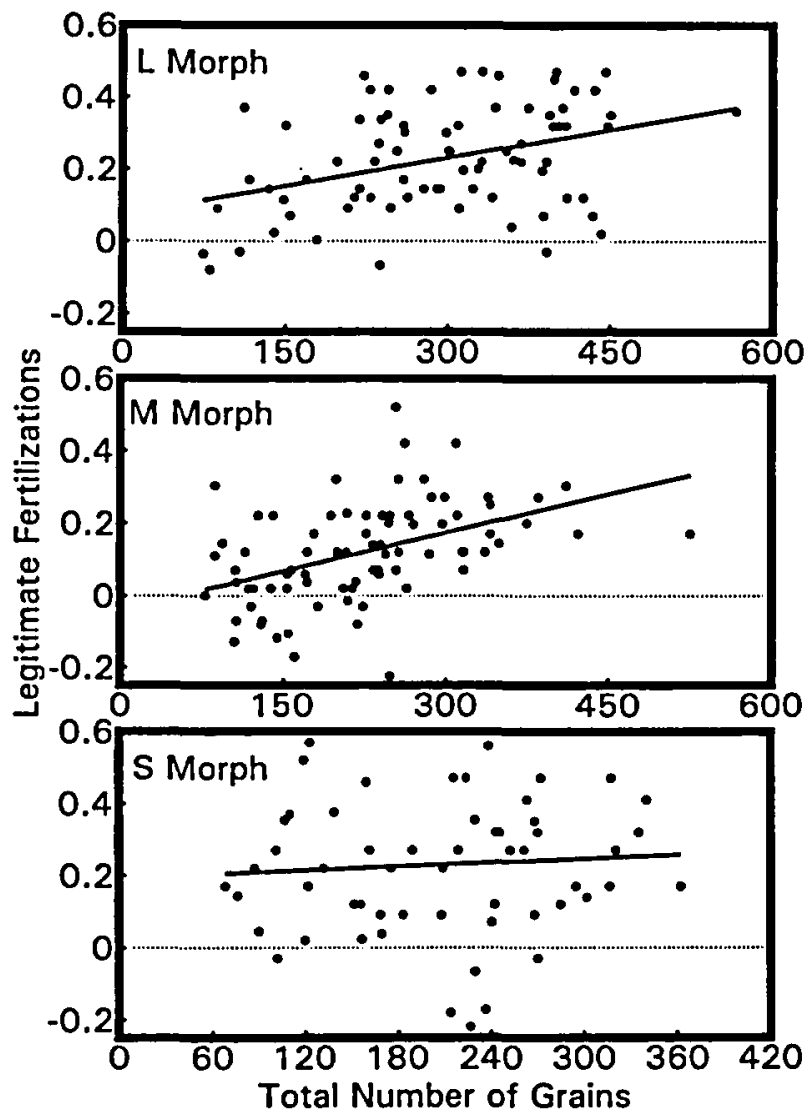

Fig. 3.-The response for the proportion of legitimate outcross fertilizations to the size of the pollen load in the three style morphs of Eichhornia paniculata. Each point represents a single pollination. Note the different scale on the $X$-axis for the $S$ morph.

functionally different patterns of mating. We further separate gamete attrition into its pre- and postfertilization stages by examining the response of seed production to varying pollen load sizes. The models described allow the identification of postpollination mechanisms that are not easily detected by traditional methods and provide predictions of the mating system and fecundity under varying pollen environments. The application of these procedures to the analysis of postpollination mechanisms in Eichhornia paniculata illustrates how an inferential analysis of reproductive processes can lead to new insights into the mating system of a species.

Previous work on $E$. paniculata suggested that differences in pollen tube growth among pollen types were largely responsible for the high outcrossing rates observed in this self-compatible species (Cruzan and Barrett 1993). Observations of pollen tubes indicated that legitimate pollen tubes reached the ovary at a higher frequency than illegitimate pollen tubes in all three morphs. The fertilization 
TABLE 3

Mean Pollen load Size, Seed Production, and tue Siring Success of Each Pollen Type in EichHornia paniculata

\begin{tabular}{|c|c|c|c|}
\hline Variable & $\begin{array}{l}\text { L Morph } \\
(N=52)\end{array}$ & $\begin{array}{l}\text { M Morph } \\
(N=53)\end{array}$ & $\begin{array}{l}\text { S Morph } \\
(N=46)\end{array}$ \\
\hline \multicolumn{4}{|l|}{ Pollen load: } \\
\hline Mean & 251.2 & 213.5 & 153.6 \\
\hline Range & $75-451$ & $88-531$ & $58-298$ \\
\hline Error & 13.5 & 12.4 & 10.0 \\
\hline \multicolumn{4}{|c|}{ Seed number: } \\
\hline Mean & 72.3 & 72.6 & 42.7 \\
\hline Range & $7-123$ & $4-113$ & $6-102$ \\
\hline Error & 4.6 & 4.2 & 3.6 \\
\hline \multicolumn{4}{|c|}{ Fertilizations: } \\
\hline \multicolumn{4}{|c|}{ I Pollen: } \\
\hline Mean & .21 & .10 & -.20 \\
\hline Error & .02 & .02 & .02 \\
\hline \multicolumn{4}{|c|}{ m Pollen: } \\
\hline Mean & .08 & .09 & .02 \\
\hline Error & .02 & .02 & .02 \\
\hline \multicolumn{4}{|l|}{ s Pollen: } \\
\hline Mean & -.28 & -.19 & .19 \\
\hline Error & .01 & .02 & .02 \\
\hline
\end{tabular}

NorE.-Fertilization success is given as a deviation from the expected value.

advantage of legitimate pollen was confirmed with genetic markers. Since pollen load sizes were not varied, however, it was not possible to determine whether differential attrition or growth rate was responsible for the observed patterns. The present study corroborates our earlier results and further elucidates the particular mechanisms responsible for the siring advantage of legitimate pollen in the three style morphs of $E$. paniculata.

The relative importance of the mechanisms responsible for discrimination among the three pollen types differed among the style morphs of E. paniculata. In the $S$ morph the siring advantage of legitimate pollen appears to be largely the result of the attrition of pollen tubes in the style, whereas in the $\mathrm{L}$ and $\mathrm{M}$ morphs discrimination among pollen types is based on the relative competitive abilities of the pollen types. Supporting evidence for different mechanisms controlling mating in the morphs comes from the relationships between seed production and seed-siring success of the pollen types across a range of pollen load sizes. Gamete attrition as indicated by the seed by regression slopes of pollen load size occurred in all three style morphs; however, the level of attrition was similar for all pollen types in the $\mathbf{L}$ and $M$ morphs, which resulted in small differences in differential gamete attrition values. In the $\mathrm{S}$ morph, on the other hand, gamete attrition was significantly greater for illegitimate than legitimate pollen. This resulted in a higher level of average gamete attrition in this morph $(\bar{d}=0.49$, compared with 0.40 in the $\mathrm{L}$ and $\mathrm{M}$ morphs) and, as the result of a positive $\delta_{i}$ value for legitimate pollen, an intercept that was greater than one for the relationship between legitimate fertilization and pollen load size. 


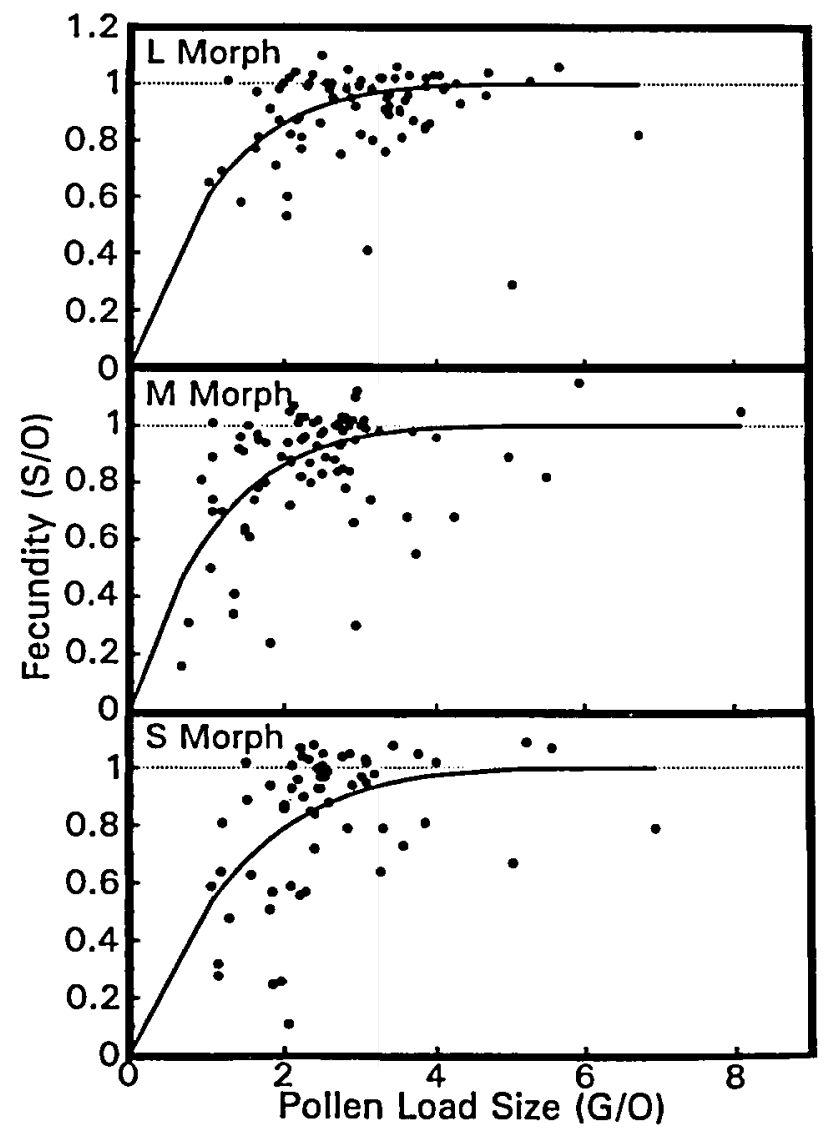

Fic. 4.-The effect of pollen load size on fecundity in the three floral morphs of Eichhornia paniculata. The lines represent the best fit to the data with nonlinear regression with equation (4). Fecundity values greater than one occurred because ovule numbers were estimated from seed data on each inflorescence (see text).

Further evidence of higher levels of gamete attrition for illegitimate pollen in the $\mathrm{S}$ morph was obtained by comparing pollinations with different proportions of legitimate pollen. The even and biased treatments (33\% vs. $50 \%$ legitimate pollen) can be compared with pollen load sizes held constant to determine whether seed set values would be greater when a larger proportion of pollen present on the stigma is legitimate. As predicted, seed numbers were greater for the biased treatment in the $\mathrm{S}$ morph (means $=92.2$ and 68.9 for the biased and equal treatments, respectively; $F=3.90, \mathrm{df}=1,68, P=.052$ ) but not in the $\mathrm{L}$ and $\mathrm{M}$ morphs ( $\mathrm{L}$ morph, means $=110.9$ and $90.9, P=.813 ; \mathrm{M}$ morph, means $=97.5$ and $83.2, P=.232$ ). In the short-styled morph, illegitimate pollen types are apparently not as effective at siring seeds as legitimate pollen.

The contrasting mechanisms controlling pollen-pistil interactions in the three floral morphs of $E$. paniculata are consistent with a recent model of the evolution 
of heterostyly proposed by Lloyd and Webb (1992a). These authors suggest that incompatibility phenomena in heterostylous plants are likely to evolve after the establishment of the morphological differences that characterize heterostyly and, hence, may develop quite separately in each floral morph. Following this model, the mechanisms responsible for failure of illegitimate pollen may differ between the morphs depending on their particular morphological and developmental features. This view is corroborated by the observation that the site of pollen tube inhibition and the strength of the incompatibility reaction often differ among morphs in other heterostylous species (reviewed in Richards 1986; Barrett and Cruzan 1994). The different functional responses observed in the $L$ and $M$ morphs compared with the $S$ morph in $E$. paniculata may be a reflection of constraints associated with the evolution of the tristylous syndrome.

Gamete attrition in the $S$ morph appears to act prezygotically rather than occur after ovule fertilization. As predicted from equation (3) and figure $1 B$, if gamete attrition were acting postzygotically in the $S$ morph, then maximum seed set should be substantially lower than the maximum seed set found in the other two morphs. Comparison of the top $20 \%$ of stigma load sizes for the three morphs, however, reveals no difference in their mean seed numbers $(109.4,106.9$, and 101.9 for the $\mathrm{L}, \mathrm{M}$, and $\mathrm{S}$ morphs, respectively; $F=0.28$, df $=2,46, P>.760$ ). This result is consistent with previous observations of low rates of ovule abortion in E. paniculata (5\%-10\%; Morgan and Barrett 1989) and indicates that illegitimate pollen types in the $S$ morph are subject to higher rates of attrition during pollen tube growth. The reduced fertilization ability of pollen growing in styles of the $\mathbf{S}$ morph and the consequent lower seed production may be detrimental when pollinator service is limited.

While the experimental procedures described can help elucidate the relative contribution of postpollination processes to mating patterns, it is important to recognize the limitations of this approach. The predictive power of results from mixed-donor pollinations will depend on the degree to which the pollen mixtures mimic those occurring under natural conditions. Little is known about the size and composition of pollen loads in natural populations of most species, including E. paniculata (but see Thomson and Stratton 1985; Thomson and Thomson 1989; and examples from heterostylous plants summarized in Ganders 1979; Lloyd and Webb 1992b). The sources of pollen included in mixtures can influence the relative success of each pollen type in a variety of ways. These include differences in pollen tube growth rate (e.g., if self pollen were mixed with outcross pollen from different distances; Waser et al. 1987), pollen-pollen interactions that affect growth rate or attrition (e.g., pollen "mentoring"; Visser 1983; Bertin and Sullivan 1988; Cruzan 1990; or pollen allelopathy; Sukhada and Jayachandra 1981; Thomson et al. 1981), or patterns of ovule abortion that depend on the genetic constitution of developing zygotes (e.g., preferential abortion of selfed ovules when outcrossed ovules are present; Rigney et al. 1993; Rigney 1995). The models described will accurately detect differences in pollen competitive ability and attrition produced by each of these mechanisms; however, the results may be specific for the particular combination of pollen sources used in the mixture. It is possible that high rates of ovule abortion could obscure patterns produced by prefertiliza- 
tion processes, but this was not an issue in the current study with $E$. paniculata. Further complications may result if pollen or zygote interactions are frequency dependent (see, e.g., El-Kassaby and Ritland 1992; Carney et al. 1994), in which case a nonlinear response to changes in the proportion of pollen types in the mixture would be expected. Such a frequency-dependent response apparently did not occur in $E$. paniculata since the patterns of deviations from expected fertilization were similar for the equal and biased treatments.

The ephemeral nature of the aquatic habitats in which $E$. paniculata is found enforces an annual life cycle and makes the reliable production of seed crucial for the maintenance of populations and colonization of new sites. The competition-based mechanism of pollen discrimination found in the $L$ and $M$ morphs would be expected to promote the production of mostly outcrossed progeny when pollinators are abundant (i.e., resulting in large pollen loads on stigmas). Since pollen types are equally capable of fertilization, seed production would be likely to remain relatively high even if pollinator activity were low (small pollen loads). The advantage of this flexibility for animal-pollinated annual species with competition-based mating systems has been previously noted (Bowman 1987; Becerra and Lloyd 1992; Cruzan and Barrett 1993). The lack of prezygotic inhibition of self pollen, however, also carries the potential disadvantage of producing a higher proportion of selfed progeny when pollinator service is unreliable. Inbreeding depression after self-pollination is known to occur in E. paniculata (Barrett and Charlesworth 1991). The overriding necessity for reproductive assurance in annual species, combined with the observation that highly selfing plant populations can be subject to genetic load (Ågren and Schemske 1993; Jarne and Charlesworth 1993), suggests that there would be a selective advantage to competition-based mating systems in many annual species.

An example of the potential consequences of competition-based pollen discrimination can be seen in E. paniculata, in which the different mechanisms controlling mating in the three style morphs may influence the morph structure of populations. Surveys in northeastern Brazil have revealed that the $S$ morph is often at low frequencies in trimorphic populations, and it is the morph that is most often absent in dimorphic populations (Barrett et al. 1989; Barrett and Husband 1990). Individuals of the $S$ morph may be at a disadvantage when pollinator activity is low. When pollinators are rare, S-morph plants would be expected to suffer lower seed production than the $\mathrm{L}$ and $\mathrm{M}$ morphs given their attrition-based mating system. Reduction in seed production by the $\mathrm{S}$ morph may contribute to its loss from populations. Under equilibrium conditions (i.e., all three morphs at equal frequencies) the dominant $S$ allele governing expression of the $S$ morph is at a lower frequency than alleles governing expression of the $\mathrm{L}$ and $\mathrm{M}$ phenotypes (Barrett et al. 1989). It has been proposed that this difference in frequencies of alleles combined with fluctuations in population size is largely responsible for the more frequent loss of the S morph from populations (Heuch 1980; Barrett et al. 1989). The additional disadvantage of reduced fecundity for individuals of the $S$ morph would further exacerbate the tendency for the $S$ allele to be lost. These considerations lead to the prediction that the $S$ morph is likely to have reduced 
female fertility in comparison with the $\mathrm{L}$ and $\mathrm{M}$ morphs, particularly where pollination service is low owing to local environmental or demographic conditions.

The above example serves to illustrate the utility of quantitative analyses of postpollination processes and represents one of the first attempts to develop inferential techniques that distinguish among mechanisms of differential siring success. The application of these models will allow the study of reproductive processes under conditions that more closely mimic natural pollination and facilitate the identification of mechanisms that control the frequency of selfing; and outcrossing in plants. Reproductive biologists have identified a number of mechanisms that affect the siring success of different pollen types (e.g., selfincompatibility, cryptic self-incompatibility, selective fertilization, selective ovule abortion, etc.). Each of these mechanisms will produce proximate effects that could be interpreted either as differences in the competitive ability of pollen or as pre- or postfertilization gamete attrition. To gain an appreciation of how these mechanisms might contribute to mating system variation, it is useful to examine them in the context of the models introduced above.

Inhibition of self pollen can result either in reduced rates of germination on the stigma or in higher rates of pollen tube failure during growth in the style (Nettancourt 1977). The degree to which self-incompatibility increases the rate of prezygotic attrition of self gametes depends on the strength of the incompatibility reaction. Very strong incompatibility reactions are probably common (Emmerson 1938; Campbell and Lawrence 1981; Levin 1993) and would result in high rates of outcrossing (see, e.g., Abbott and Forbes 1993). Weaker expression of selfincompatibility, resulting in lower rates of pollen tube attrition, are also found (Cooper and Brink 1940; Sayers and Murphy 1966; Cruzan 1989; Manasse and Pinney 1991; Montalvo 1992; Plitmann 1993), but such cases of weak differences in attrition may not always be discernable from single-donor experiments. For example, higher levels of pollen tube attrition for self pollen may not be detected with large pollen loads (i.e., as long as a sufficient number of pollen tubes reach the ovary to produce full seed set; Montalvo 1992), but even a small difference in the rate of pollen tube attrition will produce an increase in the frequency of outcrossed progeny after pollination with mixed loads (fig. $1 A$ ).

Competition-based mating systems have previously been described in apparently self-compatible species as cryptic self-incompatibility (Bateman 1956). The selective advantage of competition-based mating in self-compatible species has led to speculation about its widespread occurrence, but in fact this phenomenon has only been convincingly demonstrated by using genetic markers in a handful of cases (Weller and Ornduff 1977; Casper et al. 1988; Cruzan and Barrett 1993; Jones 1994). To determine the stage at which discrimination against self prollen occurs, genetic marker studies generally need to be combined with observations of pollen tube growth and ovule abortion patterns. The advantage of the procedure presented here is that cryptic incompatibility can be detected with genetic markers alone. Although pollen tube growth can be observed microscopically, this approach is often inadequate for the purpose of mating system studies because patterns of pollen tube growth may not reflect the siring ability of prollen 
(see, e.g., Bertin and Sullivan 1988; Montalvo 1992) and single measurements of pollen tubes cannot separate the effects of pollen tube attrition and pollen tube growth rate (see, e.g., Cruzan and Barrett 1993).

The application of genetic markers and controlled pollinations facilitates the identification of differences in the siring abilities of pollen types, and further manipulations of pollen load size allow distinctions to be made between mechanisms of differential attrition and competitive ability. Pollen load size is not normally considered in studies of pollen-siring ability after mixed pollinations. Several studies have employed genetic markers and mixed pollen loads in the analysis of differential siring ability for different pollen types (Young and Stanton 1990; Robert et al. 1991; Snow and Spira 1991; Jones 1994), and several of these have suggested that differential pollen tube growth rates are responsible for the greater siring ability of one pollen type over another (e.g., Robert et al. 1991; Jones 1994). However, without additional evidence such as changes in competitive ability under different load sizes (see above) or changes in the fertilization frequency at different distances from the ovary (Jones 1928; Pfahler 1967; Ottaviano et al. 1988; Quesada et al. 1991; Sari Gorla et al. 1992; Lau and Stephenson 1993), the hypothesis that differential attrition is responsible for differences in siring ability cannot be eliminated. Where the order of ovule fertilization is known, the rate of change in fertilization frequency can provide information about relative growth rate differences (Sari Gorla et al. 1992). For the majority of species, however, where the order of fertilization is not known, manipulation of pollen load size provides a technique for the determination of the relative contributions of gamete attrition and pollen tube growth rate to the siring abilities of pollen from different sources.

Analysis of seed production after mixed- and single-donor crosses in combination with genetic marker analysis can provide information about the relative frequency of abortion of ovules fertilized by different pollen types. Such analyses are important because they allow gamete attrition to be partitioned into its preand postfertilization components. High rates of postfertilization attrition of self pollen can reduce seed production (Krebs and Hancock 1990; Burbridge and James 1991; Waser and Price 1991; Kärkkäinen and Savolainen 1993; Seavey and Carter 1994), whereas full seed set is still possible if the failure of self gametes is due to prefertilization attrition. Establishing the stage of failure of self gametes allows an assessment of the impact of self-pollination on fecundity and establishes the potential for stylar self-incompatibility and inbreeding depression. Further studies of the genetic and ecological factors that affect fecundity and the siring success of different pollen types are likely to lead to greater insights into the proximate factors influencing mating system evolution in flowering plants.

\section{ACKNOWLEDGMENTS}

We thank M. Arnold, S. Carney, S. Hodges, and D. Manicacci for comments on the manuscript and the Natural Sciences and Engineering Research Council of Canada for financial support in the form of an operating grant to S.C.H.B. and postdoctoral fellowship support for M.B.C. 


\section{LITERATURE CITED}

Abbot, R. J., and D. G. Forbes. 1993. Outcrossing rate and self-incompatibility in the colonizing species Senecio squalidus. Heredity 71:155-159.

Ågren, J., and D. W. Schemske. 1993. Outcrossing rate and inbreeding depression in two annual monoecious herbs, Begonia hirsuta and B. semiovata. Evolution 47:125-135.

Anderson M. A., E. C. Cornish, S. L. Mau, E. G. Williams, R. Hoggart, A. Atkinson, l. Bonig, B. Grego, R. Simpson, P. J. Roche, J. D. Haley, J. D. Penschow, H. D. Niall, G. W. Tregear, J. P. Coghlan, R. J. Crawford, and A. E. Clarke. 1986. Cloning of cDNA for a stylar glycoprotein associated with expression of self-incompatibility in Nicotiana alata. Nature (London) 321:38-44.

Barrett, S. C. H. 1985. Floral trimorphism and monomorphism in continental and island populations of Eichhornia paniculata (Spreng.) Solms. (Pontederiaceae). Biological Journal of the Li:mean Society 25:41-60.

Barrett, S. C. H., and D. Charlesworth. 1991. Effects of a change in the level of inbreeding on the genetic load. Nature (London) 352:522-524.

Barrett, S. C. H., and M. B. Cruzan. 1994. Incompatibility in heterostylous plants. In E. G. Wiliams, R. B. Knox, and A. E. Clarke, eds. Genetic control of incompatibility and reproductive development in flowering plants. Kluwer, Boston.

Barrett, S. C. H., and C. G. Eckert. 1990. Variation and evolution of mating systems in seed flants. Pages 229-254 in S. Kawano, ed. Biological approaches and evolutionary trends in flants. Academic Press, San Diego, Calif.

Barrett, S. C. H., and B. C. Husband. 1990. Variation in outcrossing rates in Eichhornia paniculata: the role of demographic and reproductive factors. Plant Species Biology 5:41-55.

Barrett, S. C. H., M. T. Morgan, and B. C. Husband. 1989. The dissolution of a complex genetic polymorphism: the evolution of self-fertilization in tristylous Eichhornia paniculata (Pontederiaceae). Evolution 43:274-311.

Barrett, S. C. H., B. C. Husband, and W. W. Cole. 1993. Variation in outcrossing rates in Eichhornia paniculata: temporal changes in populations of contrasting style morph structure. Plant Species Biology 8:141-148.

Barrett, S. C. H., L. D. Harder, and W. W. Cole. 1994. Effects of flower number and pcsition on self-fertilization in experimental populations of Eichhornia paniculata (Pontederia:eae). Functional Ecology 8:526-535.

Bateman, A. J. 1956. Cryptic self-incompatibility in the wildflower: Cheiranthus cheiri L. Heredity 10:257-261.

Becerra, J. X., and D. G. Lloyd. 1992. Competition-dependent abscission of self-pollinated flowers of Phormium tenax (Agavaceae): a second action of self-incompatibility at the whole llower level? Evolution 46:458-469.

Bertin, R. I., and M. Sullivan. 1988. Pollen interference and cryptic self-fertility in Campsis radicans. American Journal of Botany 75:1140-1147.

Bowman, R. N. 1987. Cryptic self-incompatibility and the breeding system of Clarkia unguiculata (Onagraceae). American Journal of Botany 74:471-476.

Brown, A. H. D. 1990. Genetic characterization of plant mating systems. Pages 145-162 in A. H. D. Brown, M. T. Clegg, A. L. Kahler, and B. S. Weir, eds. Plant population genetics, breıding, and genetic resources. Sinauer, Sunderland, Mass.

Burbridge, A. H., and S. H. James. 1991. Postzygotic seed abortion in the genetic system of Stylidium (Angiospermae: Stylidiaceae). Journal of Heredity 82:319-328.

Campbell, J. M., and M. J. Lawrence. 1981. The population genetics of the self-incompatibility polymorphism in Papaver rhoeas. I. The number and distribution of S-alleles in families from three locations. Heredity 46:69-77.

Carney, S. E., M. B. Cruzan, and M. L. Arnold. 1994. Reproductive interactions between hybridizing irises: analyses of pollen-tube growth and fertilization success. American Journal of Botany 81:1169-1173.

Casper, B. B., L. S. Sayigh, and S. S. Lee. 1988. Demonstration of cryptic incompatibility in dis:ylous Amsinchia douglasiana. Evolution 42:248-253. 
Charlesworth, D., and B. Charlesworth. 1979. The evolution and breakdown of S-allele systems. Heredity 43:41-55.

Charlesworth, D., M. T. Morgan, and B. Charlesworth. 1990. Inbreeding depression, genetic load, and evolution of outcrossing rates in a multi-locus system with no linkage. Evolution 44: 1469-1489.

Clegg, M. T. 1980. Measuring plant mating systems. BioScience 30:814-818.

Cooper, D. C., and R. A. Brink. 1940. Partial self-incompatibility and the collapse of fertile ovules as factors affecting seed formation in alfalfa. Journal of Agriculture Research 60:453-472.

Cruzan, M. B. 1989. Pollen tube attrition in Erythronium grandiflorum. American Journal of Botany 76:562-570.

-1990. Pollen-pollen and pollen-style interactions during pollen tube growth in Erythronium grandiflorum (Liliaceae). American Journal of Botany 77:116-122.

Cruzan, M. B., and S. C. H. Barrett. 1993. Contribution of cryptic incompatibility to the mating system of Eichhornia paniculata. Evolution 47:925-934.

Cruzan, M. B., J. L. Hamrick, M. L. Arnold, and B. D. Bennett. 1994. Mating system variation in hybridizing irises: effects of phenology and floral densities on family outcrossing rates. Heredity $72: 95-105$.

Darwin, C. 1877. The different forms of flowers on plants of the same species. J. Murray, London.

Dulberger, R. 1992. Floral polymorphisms and their functional significance in the heterostylous syndrome. Pages 41-84 in S. C. H. Barrett, ed. Evolution and function of heterostyly. Springer, Berlin.

El-Kassaby, Y. A., and K. Ritland. 1992. Frequency dependent male reproductive success in a polycross of Douglas fir. Theoretical and Applied Genetics 83:752-758.

Emmerson, S. 1938. The genetics of self-incompatibility in Oenothera organensis. Genetics 23: 190-202.

Galen, C., and M. L. Stanton. 1989. Bumble bee pollination and floral morphology: factors affecting pollen dispersal in the alpine sky pilot, Polemonium viscosum (Polemoniaceae). American Journal of Botany 76:419-426.

Ganders, F. R. 1979. The biology of heterostyly. New Zealand Journal of Botany 17:607-635.

Glover, D. E., and S. C. H. Barrett. 1986. Variation in the mating system of Eichhornia paniculata (Spreng.) Solms. (Pontederiaceae). Evolution 40:1122-1131.

Hamrick, J. L., and M. J. Godt. 1990. Allozyme diversity in plant species. Pages 43-64 in A. H. D. Brown, M. T. Clegg, A. L. Kahler, and B. S. Weir, eds. Plant population genetics, breeding, and genetic resources. Sinauer, Sunderland, Mass.

Harder, L. D., and J. D. Thomson. 1989. Evolutionary options for maximizing pollen dispersal of animal-pollinated plants. American Naturalist 133:323-344.

Harding, J., C. B. Mankinen, and M. Elliot. 1974. Genetics of Lupinus. VII. Outcrossing, autofertility, and variability in natural populations of the Nanus group. Taxon 23:729-738.

Heslop-Harrison, J. 1987. Pollen germination and pollen-tube growth. Pages 59-73 in K. L. Giles and J. Prakash, eds. International review of cytology. Vol. 107. Academic Press, Toronto.

Heuch, I. 1980. Loss of incompatibility types in finite populations of the heterostylous plant Lythrum salicaria. Hereditas 92:53-57.

Holsinger, K. E. 1991. Mass-action models of plant mating systems: the evolutionary stability of mixed mating systems. American Naturalist 138:606-622.

Holsinger, K. E., M. W. Feldman, and F. B. Christiansen. 1984: The evolution of self-fertilization in plants: a population genetic model. American Naturalist 124:446-453.

Jarne, P., and D. Charlesworth. 1993. The evolution of the selfing rate in functionally hermaphroditic plants and animals. Annual Review of Ecology and Systematics 24:441-466.

Jones, D. F. 1928. Selective fertilization. University of Chicago Press, Chicago.

Jones, K. N. 1994. Nonrandom mating in Clarkia gracilis (Onagraceae): a case of cryptic selfincompatibility. American Journal of Botany 81:195-198.

Kärkkäinen, K., and O. Savolainen. 1993. The degree of early inbreeding depression determines the selfing rate at the seed stage: model and results from Pinus sylvestris (Scots pine). Heredity $71: 160-166$. 
Knox, B., C. Suphioglu, T. Hough, and M. Singh. 1992. Genetic and molecular dissection of male reproductive processes. Pages 231-254 in R. Wyatt, ed. Ecology and evolution of plant reproduction. Routledge, Chapman \& Hall, New York.

Kohn, J. R., and S. C. H. Barrett. 1992. Experimental studies on the functional significance of heterostyly. Evolution 46:43-55.

Krebs, S. L., and J. F. Hancock. 1990. Early-acting inbreeding depression and reproductive success in the highbush blueberry, Vaccinium corymbosum L. Theoretical and Applied Genetics 79:825-832.

Lande, R., and D. W. Schemske. 1985. The evolution of self-fertilization and inbreeding depression in plants. I. Genetic models. Evolution 39:24-40.

Lau, T. C., and A. G. Stephenson. 1993. Effects of soil nitrogen on pollen production, pollen grain size, and pollen performance in Cucurbita pepo (Cucurbitaceae). American Journal of Botany 80:763-768.

Levin, D. A. 1993. S-gene polymorphism in Phlox drummondii. Heredity 71:193-198.

Lloyd, D. G. 1979. Some reproductive factors affecting the selection of self-fertilization in plants. American Naturalist 113:67-79.

Lloyd, D. G., and D. J. Schoen. 1992. Self- and cross-fertilization in plants. I. Functional dimensions. International Journal of Plant Sciences 153:358-369.

Lloyd, D. G., and C. J. Webb. 1992a. The evolution of heterostyly. Pages 151-178 in S. C. H. Barrett, ed. Evolution and function of heterostyly. Springer, Berlin.

1992b. The selection of heterostyly. Pages 151-178 in S. C. H. Barrett, ed. Evolution and function of heterostyly. Springer, Berlin.

Manasse, R. S., and K. Pinney. 1991. Limits to reproductive success in a partially self-incompatible herb: fecundity depression at serial life-cycle stages. Evolution 45:712-720.

Marshall, D. L., and M. W. Folsom. 1992. Mechanisms of nonrandom mating in wild radish. Pages 91-118 in R. Wyatt, ed. Ecology and evolution of plant reproduction. Routledge, Chapman \& Hall, New York.

Montalvo, A. M. 1992. Relative success of self and outcross pollen comparing mixed-and single-jonor pollinations in Aquilegia caerulea. Evolution 46:1181-1198.

Morgan, M. T., and S. C. H. Barrett. 1989. Reproductive correlates of mating system variation in Eichhornia paniculata (Spreng.) Solms. (Pontederiaceae). Journal of Evolutionary Biology 2:183-203.

Motten, A. F., and J. Antonovics. 1992. Determinants of outcrossing rate in a predominantly selffertilizing weed, Datura stramonium (Solanaceae). American Journal of Botany 79:415-427.

Mulcahy, D. L., G. B. Mulcahy, and K. B. Searcy. 1992. Evolutionary genetics of pollen compe:ition. Pages 25-36 in R. Wyatt, ed. Ecology and evolution of plant reproduction. Routledge, Chapman \& Hall, New York.

Nettancourt, D. De. 1977. Incompatibility in angiosperms. Springer, Berlin.

Ottaviano, E., M. Sari-Gorla, and M. Villa. 1988. Pollen competitive ability in maize: within population variability and response to selection. Theoretical and Applied Genetics 76:601-61)8.

Pfahler, P. L. 1967. Fertilization ability of maize pollen grains. II. Pollen genotype, female sporophyte, and pollen storage interactions. Genetics 57:513-521.

Plitmann, U. 1993. Pollen tube attrition as related to breeding system in Brassicaceae. Plant Systematics and Evolution 188:65-72.

Quesada, M., C. D. Schlichting. J. A. Winsor, and A. G. Stephenson. 1991. Effects of genotype on pollen performance in Cucurbita pepo. Sexual Plant Reproduction 4:208-214.

Richards, A. J. 1968. Plant breeding systems. Allen \& Unwin, London.

Rigney, L. P. 1995. Postfertilization causes of differential success of pollen donors in Erythronium grandiflorum (Liliaceae): non-random ovule abortion. American Journal of Botary 82: 578-584.

Rigney, L. P., J. D. Thomson, M. B. Cruzan, and J. Brunet. 1993. Differential success of pollen donors in a self-compatible lily. Evolution 47:915-924.

Ritland, K., and F. R. Ganders. 1985. Variation in the mating system of Bidens menziesii (Asteraceae) in relation to population structure. Heredity 55:235-244. 
Robert, T., R. Lespinasse, J. Pernès, and A. Sarr. 1991. Gametophytic competition as influencing gene flow between wild and cultivated forms of pearl millet (Pennisetum typhoides). Genome 34:195-200.

Sari-Gorla, M., M. E. PÉ, D. L. Mulcahy, and E. Ottaviano. 1992. Genetic dissection of pollen competitive ability in maize. Heredity 69:423-430.

SAS Institute. 1985. SAS user's guide: statistics. SAS Institute, Cary, N.C.

Sayers, E. R., and R. P. Murphy. 1966. Seed set in alfalfa as related to pollen tube growth, fertilization frequency, and post-fertilization ovule abortion. Crop Science 6:365-368.

Schemske, D. W., and R. Lande. 1985. The evolution of self-fertilization and inbreeding depression in plants. Il. Empirical observations. Evolution 39:41-52.

Schoen, D. J., and A. H. D. Brown. 1991. Whole- and within-flower self-pollination in Glycine argyrea and $G$. clandestina and the evolution of autogamy. Evolution 45:1651-1665.

Seavey, S. R., and S. K. Carter. 1994. Self-sterility in Epilobium obcordatum (Onagraceae). American Journal of Botany 81:331-338.

Shore, J. S., and S. C. H. Barrett. 1984. The effect of pollination intensity and incompatible pollen on seed set in Turnera ulmifolia (Turneraceae). Canadian Journal of Botany 62:1298-1303.

Snow, A. A. 1986. Pollination dynamics in Epilobium canum (Onagraceae): consequences for gametophytic selection. American Journal of Botany 73:139-151.

Snow, A. A., and T. P. Spira. 1991. Differential pollen-tube growth rates and nonrandom fertilization in Hibiscus moscheutos (Malvaceae). American Journal of Botany 78:1419-1426.

Sukhada, D. K., and Jayachandra. 1981. Pollen allelopathy: a new phenomenon. New Phytologist 84:739-746.

Thomson, J. D., and D. A. Stratton. 1985. Floral morphology and cross-pollination in Erythronium grandifforum (Liliaceae). American Journal of Botany 72:433-437.

Thomson, J. D., and B. A. Thomson. 1989. Dispersal of Erythronium grandiflorum pollen by bumblebees: implications for gene flow and reproductive success. Evolution 43:657-661.

Thomson, J. D., B. J. Andrews, and R. C. Plowright. 1981. The effect of foreign pollen on ovule development in Diervilla lonicera (Caprifoliaceae). New Phytologist 90:777-781.

Uyenoyama, M. K. 1988. On the evolution of genetic incompatibility systems: incompatibility as a mechanism for the regulation of outcrossing distance. In R. E. Michod and B. R. Levin, eds. The evolution of sex. Sinauer, Sunderland, Mass.

Visser, T. 1983. A comparison of the mentor and pioneer pollen techniques in compatible and incompatible pollination of pear and apple. Pages 229-236 in D. L. Mulcahy and E. Ottaviano, eds. Pollen: biology and implications for plant breeding. Elsevier Science, New York.

Waser, N. M., and M. V. Price. 1991. Reproductive costs of self-pollination in Ipomopsis aggregata (Polemoniaceae): are ovules usurped? American Journal of Botany 78:1036-1043.

Waser, N. M., M. V. Price, A. M. Montalvo, and R. N. Gray. 1987. Female mate choice in a perennial herbaceous wildflower, Delphinium nelsonii. Evolutionary Trends in Plants 1:29-33.

Weller, S. G., and R. Ornduff. 1977. Cryptic self-incompatibility in Amsinckia grandiffora. Evolution $31: 47-51$.

Young, H. J., and M. L. Stanton. 1990. Influence of environmental quality on pollen competitive ability in wild radish. Science (Washington, D.C.) 248:1631-1633. 